\title{
Article \\ Mechanical Control of Cell Migration by the Metastasis Suppressor Tetraspanin CD82/KAI1
}

\author{
Laura Ordas ${ }^{1}$, Luca Costa ${ }^{1}$, Anthony Lozano ${ }^{1,2}{ }^{\circledR}$, Christopher Chevillard ${ }^{1}$, Alexia Calovoulos ${ }^{1} \mathbb{C}_{\text {, }}$ \\ Diala Kantar ${ }^{3}$, Laurent Fernandez ${ }^{1,4}$, Lucie Chauvin ${ }^{5}$, Patrice Dosset ${ }^{1}$, Christine Doucet ${ }^{1}$, \\ Lisa Heron-Milhavet ${ }^{3}\left(\mathbb{D}\right.$, Elena Odintsova ${ }^{6}\left(\mathbb{D}\right.$, Fedor Berditchevski ${ }^{6}$, Pierre-Emmanuel Milhiet ${ }^{1, *}$ \\ and Christine Bénistant ${ }^{1, *}$
}

1 Centre de Biologie Structurale (CBS), CNRS, INSERM, University Montpellier, 34090 Montpellier, France; laura.ordas@inserm.fr (L.O.); costa@cbs.cnrs.fr (L.C.); anthonylozano0@gmail.com (A.L.); chris.chevillard@gmail.com (C.C.); alexia.calovoulos@outlook.fr (A.C.); laurentfernandez281288@gmail.com (L.F.); pat@cbs.cnrs.fr (P.D.); christine.doucet@cbs.cnrs.fr (C.D.)

2 Institut de Génétique Moléculaire de Montpellier, University Montpellier, CNRS, 34293 Montpellier, France

3 Institut de Recherche en Cancérologie de Montpellier (IRCM), Inserm U1194-University Montpellier-Institut Régional du Cancer de Montpellier (ICM), 34298 Montpellier, France; diala.kantar@inserm.fr (D.K.); lisa.heron-milhavet@inserm.fr (L.H.-M.)

4 European Institute of Chemistry and Biology (IECB), University of Bordeaux, 33607 Pessac, France

5 Centre de Recherche de Biologie Cellulaire de Montpellier (CRBM), CNRS UMR 5237, University Montpellier, 34293 Montpellier, France; lucie.chauvin@crbm.cnrs.fr

6 Institute of Cancer and Genomic Sciences, University of Birmingham, Edgbaston, Birmingham B15 2TT, UK; e.odintsova@bham.ac.uk (E.O.); F.BERDITCHEVSKI@bham.ac.uk (F.B.)

check for updates

Citation: Ordas, L.; Costa, L.;

Lozano, A.; Chevillard, C.;

Calovoulos, A.; Kantar, D.;

Fernandez, L.; Chauvin, L.; Dosset, P.

Doucet, C.; et al. Mechanical Control of Cell Migration by the Metastasis Suppressor Tetraspanin CD82/KAI1. Cells 2021, 10, 1545. https://doi.org/ $10.3390 /$ cells 10061545

Academic Editor: Staffan Strömblad

Received: 6 April 2021

Accepted: 15 June 2021

Published: 18 June 2021

Publisher's Note: MDPI stays neutral with regard to jurisdictional claims in published maps and institutional affiliations.

Copyright: (c) 2021 by the authors. Licensee MDPI, Basel, Switzerland. This article is an open access article distributed under the terms and conditions of the Creative Commons Attribution (CC BY) license (https:// creativecommons.org/licenses/by/ $4.0 /)$.
* Correspondence: pierre-emmanuel.milhiet@cbs.cnrs.fr (P.-E.M.); christine.benistant@cbs.cnrs.fr (C.B.)

\begin{abstract}
The plasma membrane is a key actor of cell migration. For instance, its tension controls persistent cell migration and cell surface caveolae integrity. Then, caveolae constituents such as caveolin-1 can initiate a mechanotransduction loop that involves actin- and focal adhesion-dependent control of the mechanosensor YAP to finely tune cell migration. Tetraspanin CD82 (also named KAI-1) is an integral membrane protein and a metastasis suppressor. Its expression is lost in many cancers including breast cancer. It is a strong inhibitor of cell migration by a little-known mechanism. We demonstrated here that CD82 controls persistent 2D migration of EGF-induced single cells, stress fibers and focal adhesion sizes and dynamics. Mechanistically, we found that CD82 regulates membrane tension, cell surface caveolae abundance and YAP nuclear translocation in a caveolin-1dependent manner. Altogether, our data show that CD82 controls 2D cell migration using membranedriven mechanics involving caveolin and the YAP pathway.
\end{abstract}

Keywords: cell migration; plasma membrane; tetraspanins; caveolins; focal adhesions; actin; mechanotransduction; YAP

\section{Introduction}

Cell migration is a necessary process during embryonic development and can be subverted in pathologies such as cancer metastasis. Cell migration is a complex and multi-factorial process allowing cells to migrate from a primary site to a secondary site, where they will proliferate and cause fatal lesions. Major steps in carcinoma metastasis are: (1) epithelial cells are released from cell-cell contacts by epithelial-to-mesenchymal transition (EMT); (2) cell migration across the basement membrane and underlying tissues; (3) intravasation into blood vessels and extravasation from blood vessels to the metastasis place; and (4) establishment of metastatic niches, mesenchymal to epithelial transition (MET), and dormancy or aberrant proliferation [1]. The existence of specialized program for metastasis formation is sustained by the discovery of metastasis-suppressor genes [2], which encode products that are specifically involved in cell migration and invasion for 
metastasis. Tetraspanin CD82, also named KAI1, falls into this category [3]. It is a member of the tetraspanin family ( 33 members) which are characterized by four transmembrane domains that separate two extracellular domains. Most tetraspanins are glycosylated on extracellular domains and palmitoylated at juxtamembrane intracellular cysteines. They are dynamic proteins diffusing within the plasma membrane and can assemble into dynamic tetraspanin-enriched microdomains in permanent exchange with the rest of the membrane [4].

CD82 is expressed in most cells and its expression is lost early during tumor progression in various tissues including prostate and breast cancers. Conversely, its presence indicates good prognostics for several cancers [5]. CD82 anti-metastatic effect has been linked to its ability to inhibit cell migration in Boyden chambers and in wound healing assays [6,7], to impact actin polymerization and Rho-GTPases signaling [8], EMT [9], clustering/signaling of integrins and receptors such as the epidermal growth factor receptor (EGFR), transforming growth factor $\beta$ (TGF $\beta$ ) and cMET $[6,10,11]$, and to modify cell glycolipid composition [12]. In addition, CD82 regulates post-intravasation events such as cell elimination by DARC receptors in endothelial cells of blood vessels [13] and in the metastatic niche formation [14]. Its expression also inhibits EGF-induced 2D cell migration [6], further investigated in this work at the single-cell level. All these effects led us to speculate that CD82 may affect cell properties common to all these functions, especially those associated with the plasma membrane and we have considered membrane tension as a very good candidate.

Indeed, membrane tension has been shown to regulate many cell functions involving CD82, especially those linked to cell migration such as actin polymerization [15], cell polarization [16] or integrin clustering and positioning at the leading edge [17]. In vesicles, membrane tension arises from a combination of thermal fluctuation and lipid bending forces but, in cells, cytoskeleton organization also contributes to tension since the plasma membrane is attached to the underlying actin cortex [16]. In order to keep the membrane tension constant, cells use caveolae to buffer membrane tension changes during mechanical stresses [18]. They may also use microscale tetraspanin domains and migrasome formation as recently proposed [19]. Indeed, caveolae are small invaginations (60 $\mathrm{nm}$ diameter) of the plasma membrane that have the ability to flatten and disassemble upon an increase in membrane tension, releasing their constituents such as caveolin-1 and cavins [20]. Then, caveolin- 1 associates to actin and integrins within focal adhesions to transmit mechanotransduction signals and promotes the translocation of the mechanosensor and transcription factor YAP into the nucleus [21]. YAP then controls F-actin polymerization [22], focal adhesion maturation and cell polarity in turn by modulating the balance of Rho GTPases RhoA/Rock [23], Rac1 [24] and Focal Adhesion Kinase (FAK) [25]. Importantly, one of the YAP transcriptional targets is caveolin-1, which in turn negatively controls YAP [26] and this creates a loop that tightly controls plasma membrane mechanics during cell migration.

Our working hypothesis in this study was that CD82 could control cell migration by impairing this loop. Our data clearly demonstrate that this is the case, with CD82 regulating membrane tension, focal adhesion, caveolae mechanotransduction and YAP signaling, and strongly support a central role of CD82 as an inhibitor of cell migration by controlling membrane mechanics during cell migration.

\section{Materials and Methods}

\subsection{Materials}

Hydrocortisone, cholera toxin, EGF, Concanavalin A, cytochalasin D, laminin, antitubulin and horse serum were from Sigma-Aldrich (St. Louis, MO, USA), France. Cell light Talin-GFP, phalloïdine-Alexa 555, insulin solution, Lipofectamine and Lipofectamine RNAiMax, DMEM, DMEM/F12, Prolong Diamond, Hoestch and Opitmem were from Thermo Fisher Scientific (Waltham, MA, USA). The mAb raised against CD82 has been described elsewhere [27]. Si RNA against human CD82 (KAI 1 siRNA (h) sc-35734), anti-caveolin-1 and anti-YAP antibodies were from Santa Cruz Biotechnology, SiRNA 
against human caveolin-1 (L-003467-00-0005) and human YAP-1 (L-012200-00-0005) from Dharmacon, SiRNA against human CD82 (GCTGGGTCAGCTTCTACAAdTdT, TTGTAGAAGCTGACCCAGCdCdG) and siRNA negative control (SR-CL00-05) from Eurogentec, fetal bovine serum from Gibco, MLCT-Bio-DC cantilevers from Bruker, paraformaldehyde from Electron Microscopy Sciences, poly-dimethylsiloxane (PDMS) from Neyko, France, Cytosoft plates from Advanced Biomatrix, protease inhibitors tablets from Roche Diagnosis, fluorodishes from World Precision Instrument, and anti-mouse star 635P was Abberrior. Sir Actin was from Spirochrome. The RNAeasy extraction kit was from Qiagen, primers for qPCR were designed and ordered at Eurofins Genomics or Eurogentec, Superscript III reverse transcriptase was from Invitrogen and the SYBR Green I Master mix used for qPCR was from Roche.

\subsection{Cell Culture and Transfections}

The establishment of HB2 and HB2-CD82 cells has already been described in [6]. Briefly, cells were extracted from human milk and immortalized using SV40 large T antigen. They were infected with an empty virus (HB2-Mock that we called HB2 for simplicity) or a virus coding for CD82 (HB2-CD82) and selected using puromycin. HB2 cells were cultured in a complete DMEM medium containing glutamine, 10\% heat-inactivated fetal bovine serum (FBS), $1 \mathrm{mM}$ pyruvate, $10 \mu \mathrm{g} / \mathrm{mL}$ hydrocortisone and $10 \mu \mathrm{g} / \mathrm{mL}$ insulin. MCF10a are derived from benign proliferative breast tissue and spontaneously immortalized without defined factors. They were cultured in DMEM/F12 containing glutamine, 5\% horse serum, $10 \mu \mathrm{g} / \mathrm{mL}$ insulin, $20 \mathrm{ng} / \mathrm{mL}$ EGF, $0.5 \mu \mathrm{g} / \mathrm{mL}$ hydrocortisone, and $100 \mathrm{ng} / \mathrm{mL}$ cholera toxin and transfected with SiRNA by reverse transfection using RNAi max as described [28]. The absence of mycoplasma contamination was routinely checked using a MycoAlert Mycoplasma Detection kit from Lonza according to manufacturer instructions.

\subsection{Live Cell Imaging}

For migration experiments, cells were plated at low density in 24 -well plates in $1 \%$ serum containing medium and cultured overnight. Then, the medium was changed and cells were stimulated with $100 \mathrm{ng} / \mathrm{mL}$ EGF and imaged on a Zeiss axio-observer equipped with an incubation chamber for temperature and $\mathrm{CO}_{2}$ controls (1 image every 15 min for $24 \mathrm{~h}$ ). Single cells in the Supplementary Movies 1 and 2 were then tracked using MTrackJ (ImageJ) and migration data were analyzed using the DiPer program to obtain directionality ratio and average speeds cell by cell [29]. For Talin-GFP experiments, cells were incubated overnight according to manufacturer instructions in $1 \%$ serum, then stimulated with EGF and imaged using a spinning disk Nikon Ti Andor CSU-X1 or a Dragonfly Andor 1 in a $\mathrm{CO}_{2}$ and temperature-controlled incubation chamber. The 1 image/min during 20 min was acquired for HB2 cells and 1 image/min was acquired during 75 min for the MCF10a cells. Kymographs were extracted from the movies using the Fiji multikymograph program. For caveolin-GFP experiments, cells were transfected with the plasmid as described in [30] and imaged the day after using homemade objective-type TIRF setup equipped with a Plan Fluor $100 \times / 1.45$ NA objective (Zeiss, Le Peck, France Brattleboro, VT, USA). Wide-field imaging was used for YAP nucleo-cytoplasmic shuttling imaging using Zeiss AxioimagerZ1 or Zeiss AxioimagerZ2 upright microscopes equipped with Zeiss 40 or 63X Plan-Apochromat 1.4 oil objectives. Confocal images were taken using a Leica SP8 microscope equipped with a 63X NA1.4 oil objective using the LAS-AF software (Leica, Wetzlar, Germany).

\subsection{Membrane Tether Measurements by AFM}

Membrane tension was measured by tether extraction as described in [31]. In brief, plasma-cleaned MLCT cantilevers were coated using $2 \mathrm{mg} / \mathrm{mL}$ concanavalin A for $0.5-3 \mathrm{~h}$, rinsed and mounted on the AFM head of a nanowizard 4 microscope equipped with the CellHesion module (JPK bioAFM, NanoBruker). Cells were plated on $(40 \mu \mathrm{g} / \mathrm{mL})$ laminin-coated $35 \mathrm{~mm}$ fluorodish at low density, grown overnight and placed in 1\% serum 
medium before AFM experiments. Before each experiment, the cantilever spring constant (in $\mathrm{N} / \mathrm{m}$ ) was evaluated using the thermal noise method [32,33], whereas the inversed optical lever sensitivity (InvOls in $\mathrm{nm} / \mathrm{V}$ ) was evaluated through the acquisition of force curves onto a glass rigid surface. Cells were selected using phase-contrast microscopy and the cantilever was always placed at the maximal height above the nucleus. The following settings were used: $1 \mu \mathrm{m} / \mathrm{s}$ approach speed, $0.4 \mathrm{nN}$ contact force, $2 \mathrm{~s}$ contact time, $3 \mu \mathrm{m} / \mathrm{s}$ retraction speed, $15 \mu \mathrm{m}$ piezo amplitude, and 20 cycles per cell. Analyses were performed using the JPK software. Only curves where steps occurred at a distance over $2 \mu \mathrm{m}$ of the surface were taken into consideration to avoid confusion with adhesion effects. In additional experiments described in S2, 3 cells were first measured as control. Then, the remaining cells in the dish were treated with cytochalasin D (200 nM final concentration) or by adding 1 volume of water (hypotonic shock) for $5 \mathrm{~min}$ and 3-4 additional treated cells were measured by a time not exceeding $1 \mathrm{~h}$.

\subsection{Ultrastructural Analysis by Transmission Electron Microscopy (TEM)}

Cells grown on coverslip are fixed in $2.5 \%$ glutaraldehyde in phosphate buffer for $1 \mathrm{~h}$ RT and $24 \mathrm{~h}$ at $4{ }^{\circ} \mathrm{C}$, post fixed with $1 \%$ osmium tetroxide, dehydrated and eponembedded as described [30]. Infiltration is started by placing the coverslips in a 1:1 mixture of absolute ethanol and Epon 812 for $1 \mathrm{~h}$ and change for fresh resin 2 times $1 \mathrm{~h}$. They were placed upside-down above an Eppendorf cap full of fresh resin and placed in a $65^{\circ} \mathrm{C}$ oven. Then, Eppendorf caps were separated from coverslips by diving them in liquid nitrogen. Subsequently, Epon blocks were sectioned using an ultramicrotome (UC7 Leica) and $70 \mathrm{~nm}$ ultra-thin sections were mounted on 100-mesh collodion-coated copper grids, stained with uranyl acetate and lead citrate. The quality of the sections was checked by using low magnification micrographs (X1500). All the experiments were performed at the MEA platform of Montpellier University using a JEOL 1400 Plus electron microscope.

\subsection{Fabrication of Polydimethylsiloxane (PDMS) Gels}

We used either commercial gels Advanced Biomatrix or homemade gels prepared by mixing the dimethylsiloxane monomer with a cross-linking agent at a 1/60 ratio for soft (1-10 KPa) gels. After mixing and degassing under vacuum, the PDMS elastomers were spin-coated on glass coverslips or plates with a calculated volume to obtain a $50 \mu \mathrm{m}$ thickness. Then, gels were cured for $2 \mathrm{~h}$ at $70{ }^{\circ} \mathrm{C}$, UV sterilized, extensively rinsed with PBS, coated for $30 \mathrm{~min}$ with laminin $(40 \mu \mathrm{g} / \mathrm{mL})$ and rinsed again with PBS before being used for cell culture.

\subsection{Immunofluorescence and Confocal Microscopy}

Cells grown on glass coverslips or on PDMS gels, both coated with laminin, were fixed for 5-10 min at RT using a 3.7\% fresh paraformaldehyde (PFA) solution. For actin studies, cells were permeabilized with PBS $+0.1 \%$ TRITON X100 for 2 min. After 2 PBS washes, they were incubated with (1/40) phalloidin-alexa555 for $20 \mathrm{~min}$ at RT and (1/1000) Hoestch for 2 min, washed several times in PBS and mounted on slides in Prolong diamond or Mowiol immersion solutions. For CD82 immunolabelling, Talin-GFP-expressing cells on glass coverslips were fixed for $5 \mathrm{~min}$ at RT with 3.7\% PFA, washed in PBS and incubated in PBS supplemented with 3\% goat serum for $10 \mathrm{~min}$ at RT. Then, cells were incubated with anti-CD82 (5 $\mathrm{g} / \mathrm{mL}$ in blocking solution) for $1 \mathrm{~h}$ at RT. After 3 washes with PBS, cells were incubated with anti-mouse star 635P (1/200 in blocking solution) for $1 \mathrm{~h}$ at RT, washed, fixed in 4\% PFA for 5 min at RT, washed $2 X$ with PBS then water and mounted in Vectashield. For YAP immunofluorescence studies, cells were permeabilized for $10 \mathrm{~min}$ at RT with PBS-0.3\% TRITON X100. After PBS washes, cells were incubated with anti-YAP $(1 / 200)$ in PBS-1\% BSA for $6 \mathrm{~h}$ at $4{ }^{\circ} \mathrm{C}$ and then with anti-mouse alexa-647 $(1 / 500)$ in PBS-1\% BSA for $30 \mathrm{~min}$ at RT. Nuclei were labelled with Hoestch. Talin-GFP adhesion size quantifications were done on ImageJ as described in [23] using a 1-20 $\mu \mathrm{m}$ binning 
parameter. For actin fiber thickness quantifications, we first generated a plot-on line across cells on ImageJ and then quantified each peaks thickness on the plots.

\subsection{Cell Lysates and Western Blots}

Cells were lysed as described in [34]. Briefly, cells were washed in ice cold PBS then lysed in buffer containing $10 \mathrm{mM}$ Tris $\mathrm{pH} 7.4,150 \mathrm{mM} \mathrm{NaCl}, 0.5 \%$ TRITON X100, $60 \mathrm{mM}$ octylglucoside, $10 \mu \mathrm{m}$ NAF, $100 \mathrm{mM}$ Vanadate and protease inhibitors. Lysates were cleared by centrifugation at $10,000 \mathrm{~g}, 10 \mathrm{~min}$ at $4{ }^{\circ} \mathrm{C}$. Proteins in the lysates were separated by SDS-PAGE, transferred on nylon membranes and blot using indicated antibodies. Gel band quantifications were done on ImageJ.

\subsection{RNA Extraction, Reverse Transcription and Real-Time RT-qPCR}

RNAs were extracted from cells using RNAeasy plus kit (Qiagen) and cDNAs were prepared starting from $1 \mu \mathrm{g}$ of RNAs using the Superscript III reverse transcriptase (Invitrogen) and following manufacturer directions. Real-time quantitative PCR was then performed on cDNAs using SYBR Green I Mastermix (Roche) according to manufacturer conditions on a Light Cycler 480 device (Roche). All primers used are listed as follows, $5^{\prime}$ to $3^{\prime}$ :

CYR61_For: ACCAAGAAATCCCCCGAACC

CYR61_Rev: CGGGCAGTTGTAGTTGCATT

CTGF_For: TTCCAAGACCTGTGGGAT

CTGF_Rev: GTGCAGCCAGAAAGCTC

AREG_For: CGAAGGACCAATGAGAGCCC

AREG_Rev: AGGCATTTCACTCACAGGGG

BIRC2_For: GTCAGAACACCGGAGGCATT

BIRC2_Rev: TGACATCATCATTGCGACCCA

CD82 For: ACTGGTTTCGTGGAAGGAAG

CD82_Rev: GCGCCCAGGATAAAGAAGAT

YAP_For: GCTACAGTGTCCCTCGAACC

YAP_REV: ACTTGGCATCAGCTCCTCTC

\subsection{Statistical Analyses}

Anova analysis was used for simultaneously comparing means in several groups. Then, we used a 2-tailed unpaired $t$ test or the parametric Mann-Whitney test for side by side comparisons between 2 groups. Numbers of * are indicated and represent the significance: $1 * p<0.05,{ }^{* *} p<0.01,{ }^{* * *} p<0.001,{ }^{* * * *} p<0.0001$.

\section{Results}

3.1. CD82 Regulates Persistent Cell Migration, Both Size and Dynamics of Focal Adhesions and Actin Polymerization

CD82 has been shown to inhibit cell migration in Boyden chambers or wound healing assays $[6,14]$. We further studied its effect on EGF-induced single-cell migration assay in 2D using the human breast-derived HB2 cells. These cells have lost the expression of CD82 in the course of cell immortalization and have been infected with an empty virus (named HB2) or with a virus expressing CD82 (named HB2-CD82) [35]. HB2-CD82 cells express a large amount of CD82 as compared to HB2 cells (Figure S1A). This expression level, however, is in the range found in normal breast epithelium and represents over 5 -fold the endogenous level found in MCF10a, the closest to normal human breast cell line (Figure S2A,B).

We observed that HB2 cells that express a low level of CD82 (Figure S1A) migrated preferentially in one direction, exploring a large area (Figure 1A and Supplementary Movie S1). On the contrary, HB2-CD82 cells did not directionally migrate and have a tendency to turn around (Figure $1 \mathrm{~A}$ and Supplementary Movie S2). Accordingly, trajectories are longer in HB2 than in HB2-CD82 (Figure 1A) and both speed and directionality 
are impaired in HB2-CD82 cells (Figure 1B,C): the means $+/-$ sem are $0.35+/-0.03$ vs. $0.16+/-0.02 \mu \mathrm{m} / \mathrm{min}$ for speed and $0.30+/-0.01$ vs. $0.22+/-0.02$ for directionality ratio in HB2 vs. HB2-CD82, respectively. Similar data were obtained in MCF10a (Figure S2) that constitutively express CD82 and turned around frequently (Supplementary Movie S3), whereas MCF10a cells depleted of CD82 by siRNA had longer and straighter trajectories (Supplementary Movie S4, Figure S2C-E). As expected, the directionality ratio was increased from $0.21+/-0.13$ to $0.35+/-0.17$ in MCF10a siCtl vs. MCF10a siCD82, respectively (Figure S2D). We have concluded that CD82 impacts persistent cell migration, an important result since this can drive metastasis formation in vivo [36].
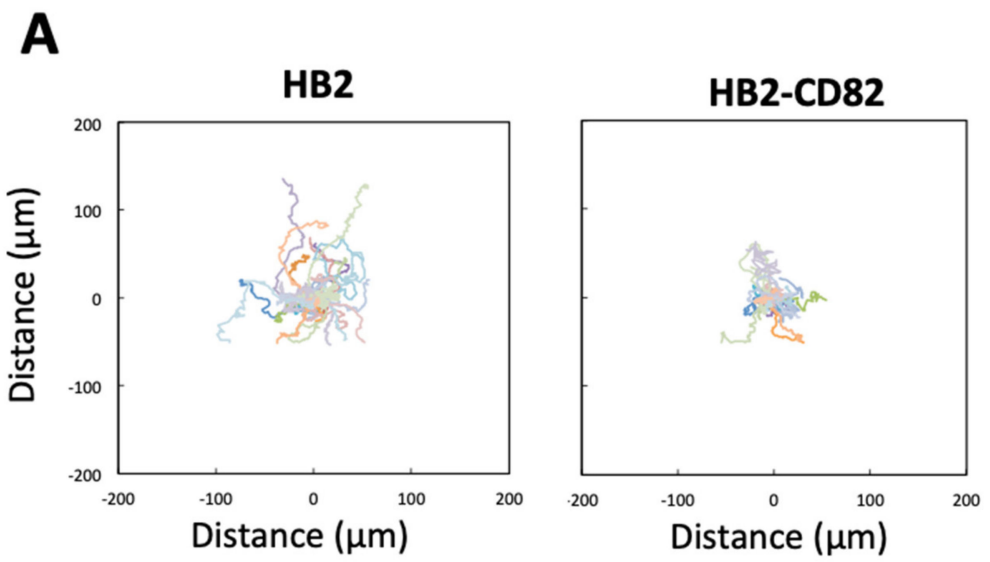

B

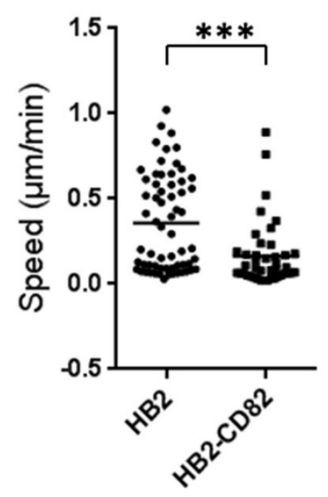

C

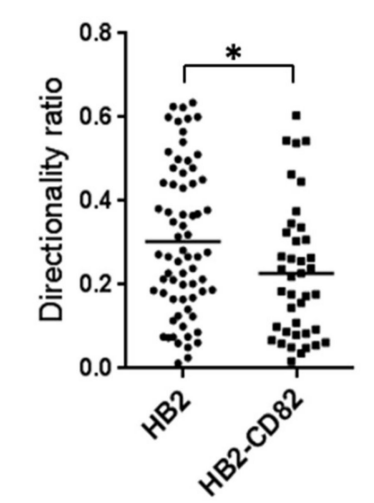

Figure 1. CD82 regulates EGF-induced single-cell persistent migration. (A) Trajectories of the 10 EGFstimulated single HB2 or HB2-CD82 cells; (B) average speed of the cells; (C) directionality ratio of the cells determined as the shortest distance between the starting and arrival points divided by the real distance traveled by the cells ( $n=68$ and 40 cells, respectively, for HB2 and HB2-CD82, obtained from 10 independent experiments), ${ }^{*} p<0.05,{ }^{* * *} p<0.001$.

As 2D cell migration relies on both focal adhesion and actin turnovers [37], we investigated the morphology of focal adhesions in HB2 and HB2-CD82 cells using the retroviral cell-light Talin-GFP (Figure 2A,B). We observed that HB2-CD82 cells have significantly more peripheral (yellow arrows in Figure 2A) and larger adhesion areas as compared to $\mathrm{HB} 2$ cells (the mean values \pm sem of their surface are, respectively, $3.01+/-0.78$ and $3.78+/-1.0 \mu \mathrm{m}^{2}$ ) (Figure $2 \mathrm{~B}$ ). We also analyzed the dynamics of adhesion sites in Talin-GFP-expressing HB2 cells using spinning disk confocal microscopy and observed that focal adhesion in HB2 cells was more dynamic than in HB2-CD82 cells, retro-sliding away from the migration front as expected for a migratory cell (Supplementary Movie S5 and Figure S1B). On the other hand, HB2-CD82 cells displayed very stable adhesions and did not migrate (Supplementary Movie S6 and Figure S1B). Thus, CD82 might fa- 
vor the formation of large mature and stable adhesion sites. Since focal adhesions are involved in building up actin stress fibers [38], we also performed actin labelling using the SiR-actin probe and observed that HB2-CD82 cells underwent a thickening of actin stress fibers (Figure 2C,D). In particular, the percentage of thin fibers (arbitrary chosen to be $<1 \mu \mathrm{m}$ diameter) over the total number of fibers was lower in HB2-CD82 as compared to HB2 cells $(26.5+/-6.8$ vs. $57.0+/-5.7$; on the other hand, the number of thick fibers $>1 \mu \mathrm{m}$ was higher in HB2-Cd82 as compared to HB2 cells $73.4+/-5.7$ vs. $42.9+/-5.7 \%$; mean $+/-$ sem).

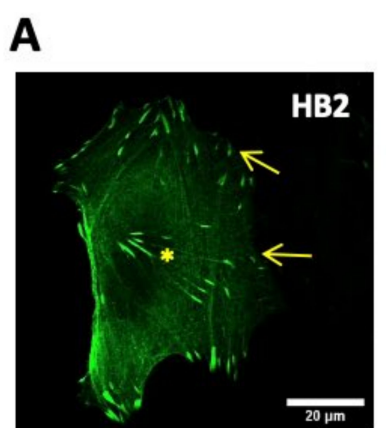

Talin-GFP

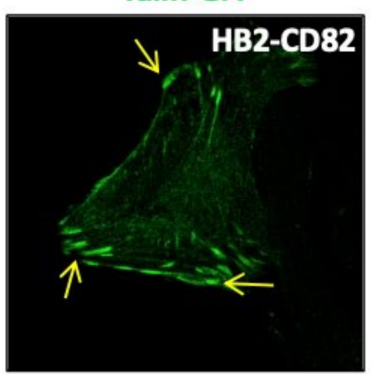

B
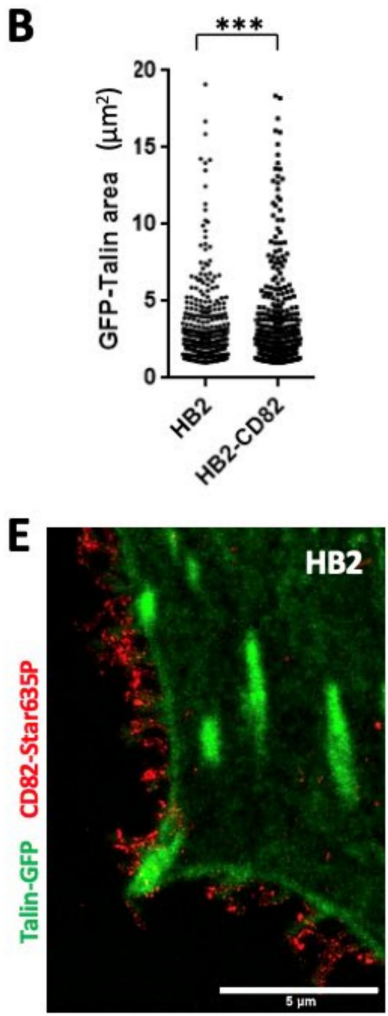

C

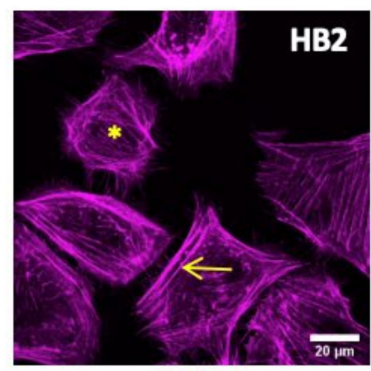

Actin

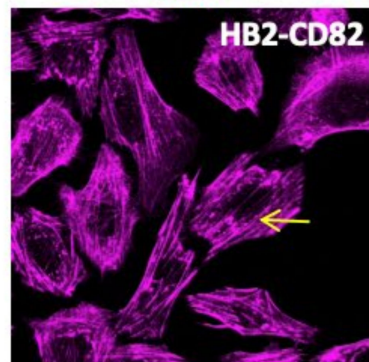

D
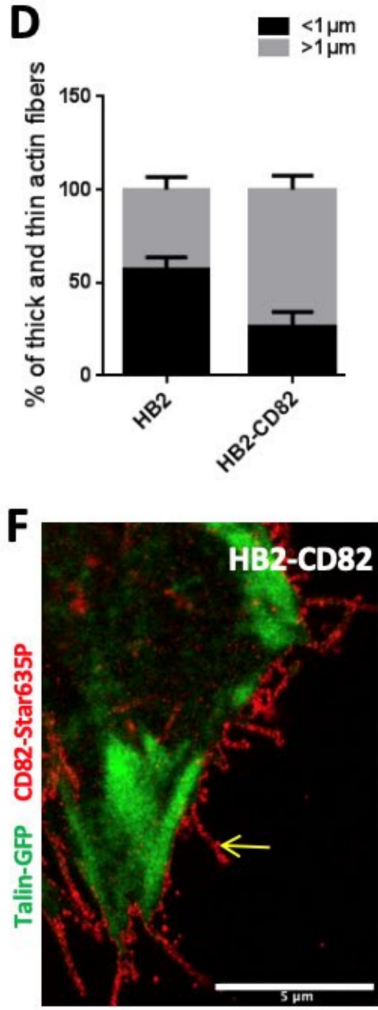

Figure 2. CD82 regulates both size and dynamics of focal adhesion and actin fiber sizes. (A) Talin-GFP labelling in HB2 and HB2-CD82 (left panel). Arrows indicate peripheral adhesions that are smaller in HB2 cells than in HB2-CD82 cells. The yellow 
asterisk indicates small central adhesions in HB2 cells. (B) Quantification of the size of the peripheral adhesions on 11 cells from 4 independent experiments, ${ }^{* * *} p<0.001$. (C) SiR actin labelling of HB2 cells and HB2-CD82 cells (right panel). Arrows point out thick fibers in HB2 and HB2-CD82 and asterisks small fibers in HB2 cells, respectively. (D) Quantification of fiber thickness using the Fiji plugin "line plot" (measurement of the width of the picks), shown as the percentage of the total number of fibers on 20 cells from 4 independent experiments (the fibers are arbitrary classified as thin or thick if their thickness is less than or greater than $1 \mu \mathrm{m}$, respectively), (E,F) Fluorescent images of CD82 (STED) and Talin-GFP (confocal) in HB2 and HB2-CD82 cells, respectively. Bar $=5 \mu \mathrm{m}$. The yellow arrow points out CD82 in a membrane extension in HB2-CD82 cells.

Importantly, MCF10a silenced using two different SiRNAs (MCF10asiCD82 1 and 2) exhibited smaller (Figure S3B,C) and more dynamic focal adhesions than MCF10a silenced with control SiRNA (MCF10aSiCtl) (Supplementary Movies S7 nad S8, Figure S3A). In addition, the percentage of thick actin stress fibers ( $>1 \mu \mathrm{m}$ apparent diameter) over the total number of fibers decreased in MCF10a silenced for CD82 as compared to the control (Figure S3D,E). From these observations, we have concluded that CD82 regulates both focal adhesion dynamics and actin stress fibers architecture both in HB2 and MCF10a cells. In order to better understand how CD82 promoted these effects, we first assessed that CD82 in HB2 cells was largely expressed at the cell surface using flow cytometry on non-permeabilized cells (Figure S1B). Interestingly, fluorescence microscopy experiments confirmed this and showed that CD82 mainly localized close to the Talin-enriched area and was often expressed in membrane projections that can arise from adhesions (appear as dotted structures using STED microscopy) (Figure 2E,F). A similar pattern in membrane projections was also observed in MCF10a cells (Figure 3E, lower panels). Taken together, these results clearly indicate that CD82 is expressed at the plasma membrane, where it can regulate cell migration, actin stress fiber sizes and focal adhesion dynamics.

A

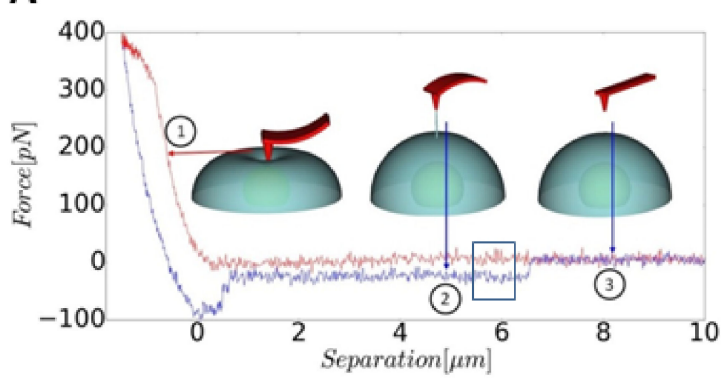

C

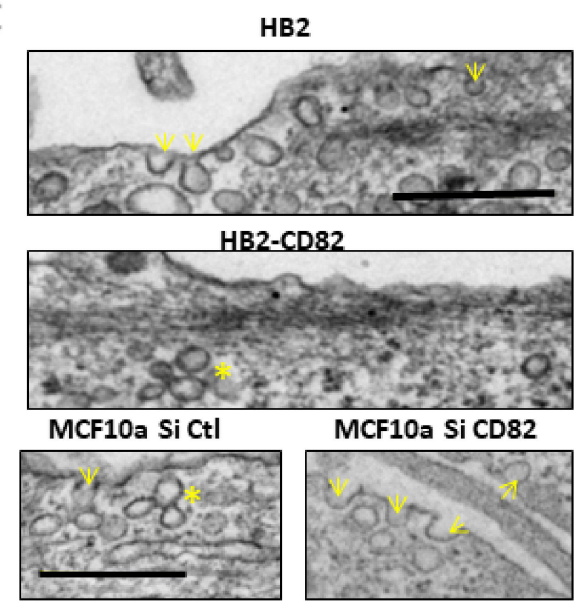

B

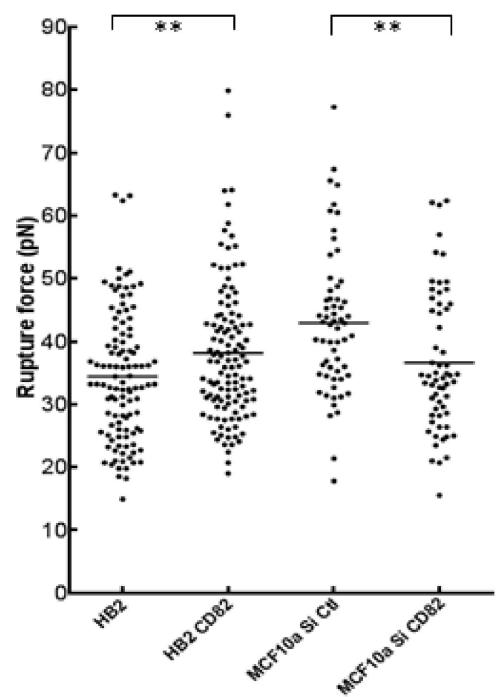

D

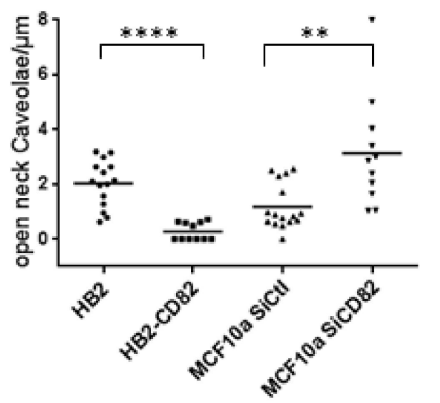

Figure 3. Cont. 

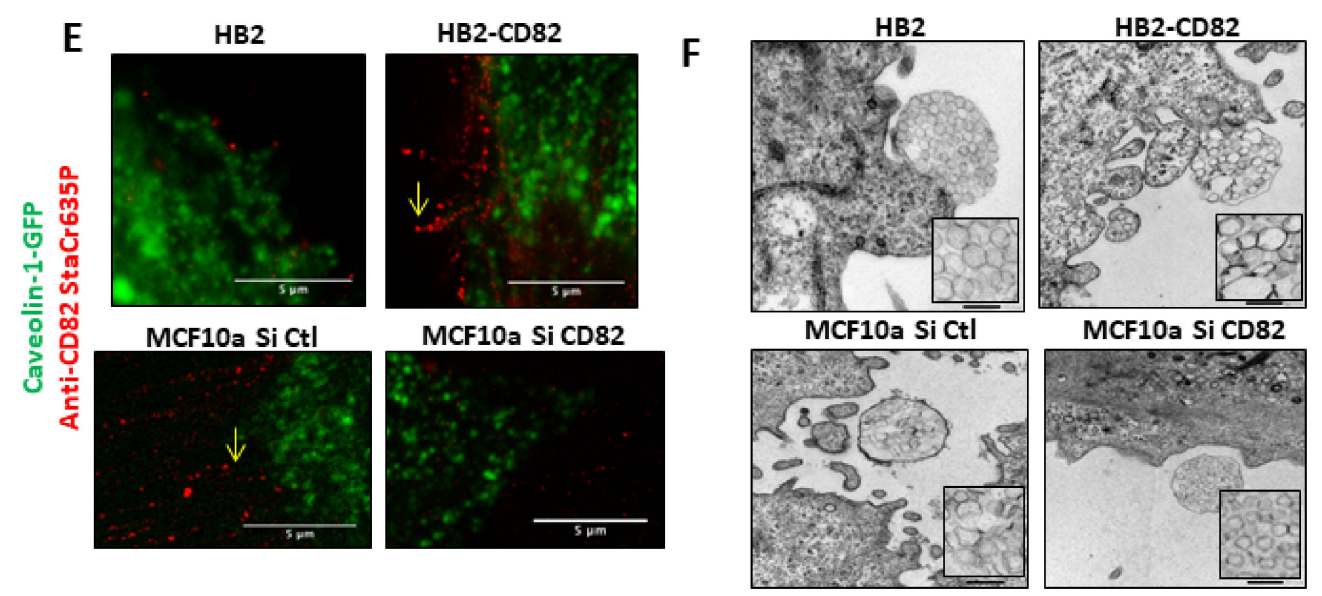

Figure 3. CD82 regulates membrane tension and the presence of cell surface caveolae in HB2 and MCF10a cells. (A) Schematic view of the membrane tether pulling experiment. The approach and retract curves are, respectively, in red and blue. Step 1 corresponds to the tip indenting the cell membrane, Step 2 to the pulling of the membrane tube during retraction and Step 3 to non-contact between the tip and the membrane. The blue rectangle highlights the rupture event between the tube and the tip where the rupture force is measured. (B) Rupture force of plasma membrane tubes as a read out of membrane tension in HB2 (110 measurements, 8 different probes, 21 cells, $n=8$ ) and HB2-CD82 cells (119 measurements, 8 different probes, 19 cells, $n=8$ ) and in MCF10a cells transfected with control siRNA ( $\mathrm{Si} \mathrm{Ctl,} 61$ measurements, 2 different probes, 7 cells, $n=3$ ) or with siRNA targeting CD82 (Si CD82, 60 measurements, 2 different probes, 8 cells, $n=3$ ); ${ }^{* *} p<0.01$. (C) TEM microscopy images of membranes of HB2 (upper), HB2-CD82 (middle), MCF10a cells transfected with siRNA control (lower left) or with siRNA targeting CD82 (lower right). Arrows indicate open-neck caveolae; ${ }^{*}$ indicate rosettes; bar $=500 \mathrm{~nm}$. (D) Quantification of the number of open-neck caveolae observed by EM and expressed per micrometer of membrane. ${ }^{* * * *} p<0.0001$; (E) Fluorescent images of CD82 (STED) and Caveolin-GFP (confocal) in HB2 (upper, left), HB2-CD82 (upper right), MCF10a si Ctl (lower left) and MCF10a si CD82 (lower, right) cells. The yellow arrow points out CD82 in a membrane extension in HB2-CD82 cells and MCF10a si Ctl. (F) TEM microscopy images of migrasomes in HB2, HB2-CD82, MCF10a si Ctl and MCF10a siCD82 (bar = $500 \mathrm{~nm}$ ); inserts enlighten vesicles inside migrasomes.

\subsection{CD82 Regulates Membrane Tension and Cell Surface Caveolae Density}

Cell polarization and persistent cell migration are associated with an important remodeling of the plasma membrane that is associated with its deformability and change in its tension [16]. Recent data have also highlighted that membrane tension controls actin polymerization [15]. We thus investigated whether CD82 affects membrane tension.

To do so, we measured membrane tension in HB2 and HB2-CD82 cells by pulling membrane tubes using ConA-decorated AFM cantilevers as previously described [31] (Figure 3A,B). The force curves obtained during this process are then analyzed to extract the rupture force (squared in Figure 3A), which is the force required to break a membrane tether and relates to the membrane tension. The rupture force measured in HB2 cells (mean $+/-$ sem) was $34.4+/-3.6 \mathrm{pN}$ and significantly different from $38.1 \mathrm{pN}+/-3.9$ measured in HB2-CD82 cells (Figure 3B). In MCF10a, we found that endogenous CD82 also regulates membrane tension. Indeed, the rupture force in MCF10a transfected with control SiRNA was $42.9+/-0.7$ and decreased to $36.6+$ / -2.9 in MCF10a transfected with SiRNA targeting CD82 (Figure 3B).

We next compared this property of CD82 to that of a mild hypo-osmotic shock (see Materials and Methods Section). We found a significant 1.2-fold increase in rupture force in HB2 cells incubated in hypoosmotic conditions as compared to non-treated cells, a magnitude of the decrease in good agreement with [17] (Figure S4A). Surprisingly, rupture forces in HB2-CD82 cells were not significantly increased by the hypoosmotic conditions, suggesting that maximal tension could have been reached (Figure S4A). Since membrane- 
to-cortex attachment control directed cell migration [16], we also probed the importance of actin cytoskeleton by measuring tether forces on cells treated with cytochalasin $\mathrm{D}, \mathrm{a}$ well-known inhibitor of actin polymerization. We found a significant decrease in the tether forces under cytochalasin D treatment in HB2-CD82 cells (Figure S4A), confirming the importance of the actin cortex in plasma membrane tension and in accordance with the changes in actin stress fibers morphology induced by CD82 described in Figure 2C,D. Since caveolae are membrane invaginations that behave as physiological membrane reservoirs and can buffer membrane tension induced by mechanical stress [18], we have then studied the effect of CD82 expression on the density of caveolae at the cell surface of HB2, HB2CD82 and MCF10a cells. We first evaluated caveolin-1 expression levels in these cell lines by Western blotting and we found that caveolin-1 was expressed to a significant level in HB2, HB2-CD82 and in MCF10a cells (Figures S1A and S2A). Next, we used transmission electron microscopy (TEM) on epon-embedded cells stained with uranyl acetate and lead citrate to observe caveolae at the plasma membrane. We found that plasma membrane of HB2 cells contains invaginations of both shape and size of caveolae (Figure 3C,D) and observed that the number of cell surface connected caveolae, measured by counting the number of open-neck caveolae per $\mu \mathrm{m}$ of membrane measured as described in [30], decreased 10-fold in HB2-CD82 cells as compared to HB2 cells (Figure 3C upper panels and Figure 3D). Mean $+/-$ sem values were $2.0+/-0.4$ and $0.2+/-0.1$ open-neck caveolae $/ \mu \mathrm{m}^{2}$ for HB2 and HB2-CD82, respectively. Similarly, we observed few vesicles of the size and shape of caveolae at the cell surface of MCF10 cells and their number significantly increased by $\sim 3$ fold at the cell surface of MCF10a transfected with siCD82 $(1.1+/-0.4$ and $3.1+/-1$ in MCF10a SiCtl and siCD82, respectively) (Figure 3C, lowers panels and Figure 3D).

We also measured the effect of a mild hypoosmotic shock on cell surface caveolae. Interestingly, we observed a reduction in cell surface caveolae in HB2 cells as described in [18] to reach the level observed in HB2-CD82 (Figure S4B). In accordance with the observation of caveolae by TEM (Figure 3C), live-TIRF microscopy on caveolin-GFP cells indicated that HB2 cells present a lot of fast-moving GFP puncta close (deep to $200 \mathrm{~nm}$ ) to the basal membrane surface that were decreased in intensity and speed upon a mild hypoosmotic shock (Supplementary Movie S9, Figure S4C,D), as described in [18]. By contrast, GFP puncta in HB2-CD82 were mainly less mobile (Supplementary Movie S10, Figure S4C,D), confirming that CD82 impacts caveolin-1-associated events. We also compared CD82 and caveolin-1-GFP localization in both non-permeabilized HB2 and MCF10a cells and observed that CD82 and caveolin-1-GFP were not colocalized (Figure 3E). We concluded that CD82 expression could impact the number of caveolae at the cell surface, consistent with its effect on membrane tension, but CD82 and caveolin-1 were not localized in the same compartment of the plasma membrane. A very recent work has shown that tetraspanins such as CD82 were involved in the formation of migrasomes, some cellular organelles that form as large vesicle-like structures, containing smaller vesicles, on retraction fibers of migrating cells [19]. Thanks to in vitro reconstitution experiments, it has been proposed that CD82 together with cholesterol could directly control membrane tension to generate these small vesicles. Interestingly, we also observed such structures by TEM in both HB2 and MCF10a cells (Figure 3F) and showed that the small vesicles in migrasomes show drastic changes in shape (Figure S5A,B) and size as a function of CD82 expression, probably reflecting the changes in membrane tension induced by CD82, the migrasomes being likely less pro-migratory when CD82 was expressed and the vesicles deformed. Altogether, these data highlighted that CD82 regulates membrane tension and caveolae at the cell surface.

\subsection{CD82 Regulates Caveolae Mechanosensing and YAP Nuclear Translocation and Activity}

The transcription factor YAP is an important mechanotransductor in cells. In response to changes in cell rigidity or shape, it translocates into the nucleus to activate specific transcriptional programs [39]. Recent data have shown that YAP also regulates actin turnover by suppressing the formation of F-actin [22]. In addition, YAP regulates the mechanosensing of adhesion sites and, in turn, adhesions regulate YAP [23]. Moreover, 
YAP is also regulated by caveolae and, in turn, YAP regulates caveolin-1 expression [21]. Thus, YAP functions appear related to CD82 properties that we described above and we then investigated the effect of CD82 on YAP mechanotransduction in HB2, HB2-CD82 and MCF10a cells.

To do so, cells were grown overnight on commercial gel-coated coverslips or coverslips coated with homemade $50 \mu \mathrm{m}$ thick silicone gels of 1-10 kPa rigidity and covered by laminin. We observed that on soft substrates, YAP was more present in the nucleus of HB2-CD82 cells as compared to HB2 cells, suggesting that HB2-CD82 cells have different mechanosensing properties than HB2 cells (Figure 4A,B).
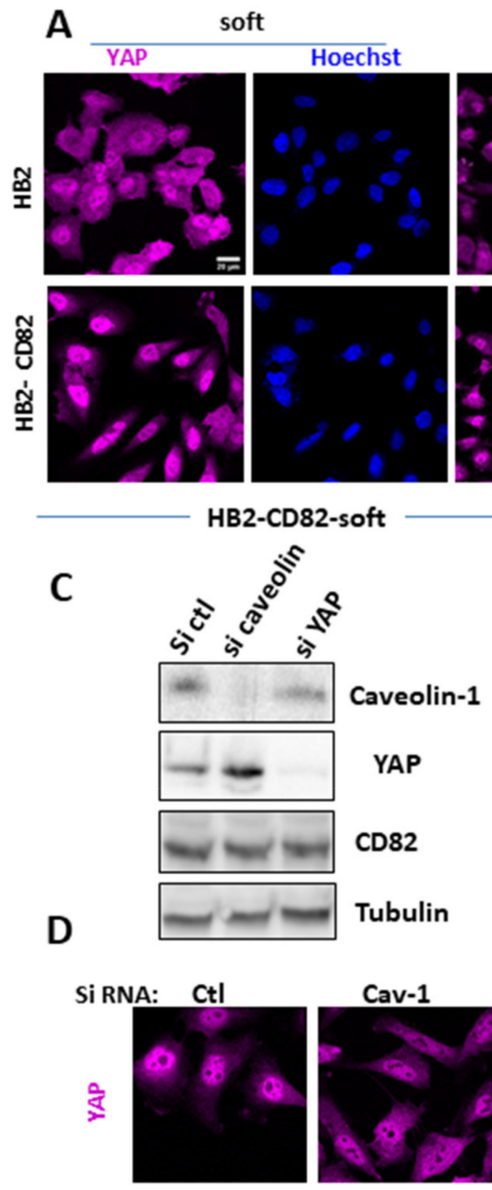

E

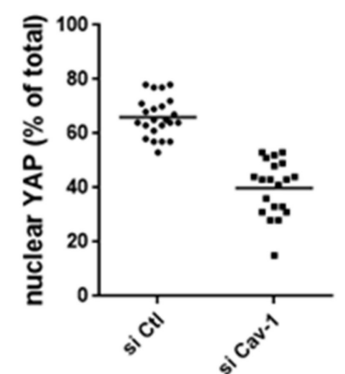

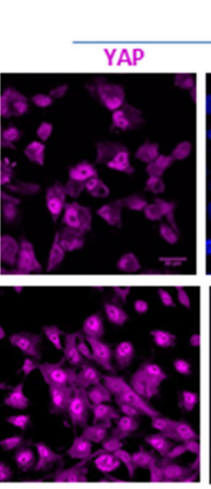

stiff

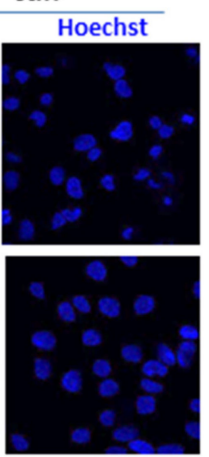

MCF10a-soft

$\mathbf{F}$

B

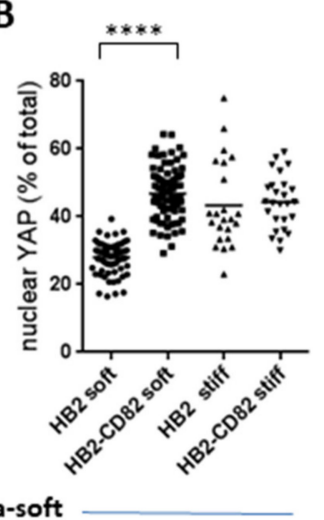

Si RNA:

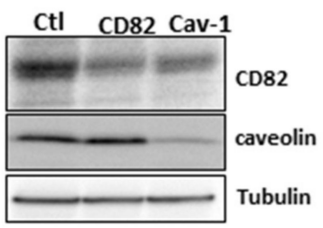

G

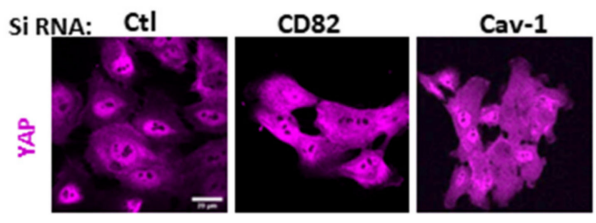

H

Figure 4. CD82 regulates caveolin-dependent YAP nuclear translocation. (A) Glass coverslips were coated with (soft, $1 \mathrm{kPa}$ ) or without (stiff, GPa) silicone gels then with laminin. HB2 and HB2-CD82 cells were cultivated overnight on these coverslips, then fixed and labelled with YAP antibodies or Hoestch to visualize nuclei (soft silicon: $n=73$ and 84 cells in HB2 and HB2-CD82 cells, respectively, $n=10$ experiments; stiff silicon: $n=23$ and 26 cells, $n=4$, respectively). Bar $=20 \mu \mathrm{m}$. (B) Nuclear YAP expressed as a percentage of the total amount; ${ }^{* * *} p<0.0001 \mathrm{~ns}$ : non-significant. (C) Caveolin, YAP and CD82 expressions in HB2-CD82 cells transfected with siRNA control (siRNA Ctl), SiRNA targeted caveolin-1 (si Cav-1) or SiRNA targeted YAP (Si YAP) grown $24 \mathrm{~h}$ on soft silicon gels coated with laminin and lysed. Tubulin is shown as a loading control. (D) Same experimental conditions as in C but cells are fixed and labelled with anti-YAP. Bar $=20 \mu \mathrm{m}$. (E) Quantification of images shown 
in D as described in B using Hoestch labelling (not shown) to visualize nuclei ( 23 and 20 cells, $n=3$ for HB2-CD82 Si Ctl and HB2-CD82 Si Cav-1): ${ }^{* * * *} p<0.0001$. (F) CD82 and caveolin-1 expression in MCF10a si Ctl, siCD82 and Si Cav-1 cultured on soft substrate (MCF10a-Soft). Tubulin is shown as a loading control. (G) YAP localization in MCF10a transfected with siRNA Ctl, siRNA targeted CD82 or Caveolin-1 and cultured on soft substrate: bar $=20 \mu \mathrm{m}$. $(\mathbf{H})$ Quantification of nuclear YAP expression in MCF10a Si Ctl $(n=31$ cells), Si CD82 $(n=40)$ and Si Cav-1 $(n=27)$ from 3 separate experiments.

This change in mechanosensitivity was also supported by the rounding up of the nucleus of HB2-CD82 cells (increase in the ellipticity ratio in Figure S5C), a marker of mechanosensitivity [40] and a property that may impact YAP nucleo-cytoplasmic shuttling [41,42]. The percentages of YAP in the nucleus in cells grown on soft substrate (Figure 4B) were $28.0+/-0.4$ and $46.8+/-0.7$ for HB2 and HB2-CD82 cells, respectively. However, no difference was observed in cells cultivated overnight on stiff glass coverslips (43.3 +/ -5.2 and $44.3+/-3.5$ in HB2 and HB2-CD82, respectively).

Since caveolin-1 controls YAP nucleo-cytoplasmic shuttling and CD82 regulates caveolae shape and size, we next studied the contribution of caveolin-1 in CD82-induced YAP nuclear translocation on soft conditions by silencing caveolin-1 expression (Figure 4C-E). Achieving 75\% silencing in HB2-CD82 cells (Figure 4C), the levels of YAP expression in the nucleus, displayed as the percentage of the total expression (mean $+/-$ sem), significantly decreased from $66.0+/-4.1 \%$ in HB2-CD82 cells transfected with Ctl SiRNA to $39.9+/-$ $5.8 \%$ in cells silenced for caveolin-1 (Figure $4 \mathrm{E}$ ). A similar effect was also observed in MCF10a cultured on soft substrate (Figure $4 \mathrm{~F}-\mathrm{H}$ ) where nuclear YAP in cells expressing the control SiRNA,- represents $46.1+/-7.6 \%$ of the total, this percentage decreasing to $32.1+/-6.8 \%$ in cells silenced for CD82 and to $26.4+/-3.0 \%$ in cells silenced for caveolin-1 (Figure 4H). In addition, we observed that CD82 endogenous level decreased in caveolin-1 MCF10a-silenced cells but this is unlikely to be due to YAP nuclear shuttling since CD82 was found not to be a target of YAP in our cell lines (see below). Since a similar effect was not observed in HB2 cells overexpressing CD82 (Figure 4C), it is likely that the stability of endogenous CD82 is impaired in caveolin-1 deficient MCF10a cells. Altogether, these data demonstrate that CD82 impacts cell mechanics and YAP nucleo-cytoplasmic shuttling mediated by caveolin-1.

YAP is a transcriptional co-regulator that can promote gene expression [39] and we next studied YAP transcriptional targets by RT-QPCR by measuring the expression of potential YAP targets in HB2 and MCF10a cells (Figures 5A, S1C,D and S3F). By downregulating YAP using SiRNA by 81 and 96\%, respectively, in HB2 and MCF10a cells, we observed downregulations of several known YAP targets such as Cyr61, CTGF and AREG (Figures S1C and S3F). However, we found that BIRC2 and CD82 are probably not targets of YAP in MCF10a (Figure S3F). This hypothesis was also confirmed at the level of CD82 protein in YAP-depleted HB2 cells where CD82 expression was not significantly altered by YAP downregulation, whereas we did observe a net increase in YAP expression in caveolin1-depleted HB2-CD82 cells (Figure 4C) as described [21]. Although YAP downregulation was strong, the amount of target genes was only decreased by about $50 \%$. This is probably because YAP was highly expressed and that the remaining YAP is sufficient to exert some transcriptional activity. In addition, it is generally necessary to downregulate both YAP and TAZ to achieve a complete transcriptional inhibition [22]. We also analyzed the effect of CD82 expression on the validated YAP targets. We first observed that CD82 regulates YAP targets in both cell lines (Figures 5A and S1D). For example, AREG mRNA is increased in CD82-overexpressing HB2 cells $(1.42+/-0.28$, mean $+/$ - sem, $n=3$ experiments $)$ and decreased in MCF10a cells knock down for CD82 by siRNA (Figures 5A and S1D). As another example, CYR61 mRNA levels are decreased down to $0.29 \%+/-0.01$ (mean + / - sem, $n=3$ experiments) by CD82 knockdown in MCF10a as compared to control (Figure 5A). Interestingly, knock down experiments in MCF10a give stronger effects when compared to overexpression experiment, probably because cells can better tolerate CD82 overexpression. However, we did not observe major differences in YAP target gene expression in stiff vs soft conditions. On one hand, this is not surprising since a $\sim 95 \%$ reduction in YAP 
expression induces only a 50\% target gene inhibition (Figure S3F) while we expected only a $10 \%$ difference for a $25 \%$ difference in nuclear YAP between stiff vs soft conditions. On the other hand, this indicates that nuclear YAP activity in stiff conditions is still regulated by CD82 and YAP has probably not the same activity when CD82 is present.

A

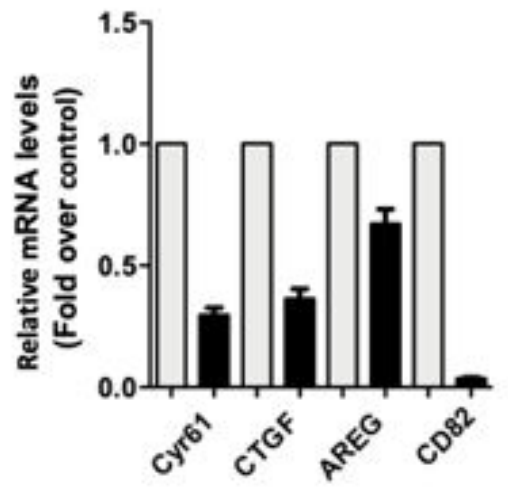

B

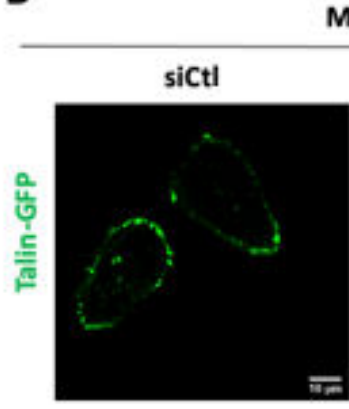

MCF10a

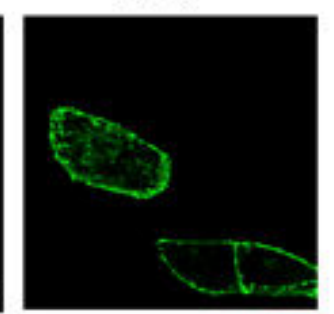

D

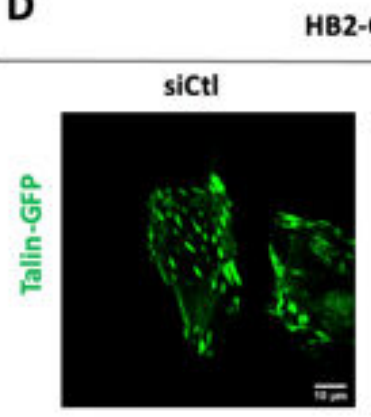

HB2-CD82

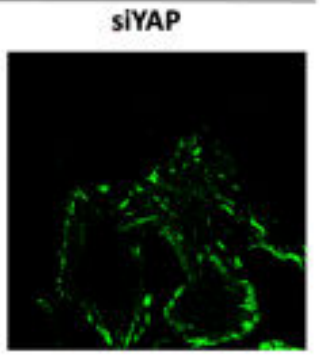

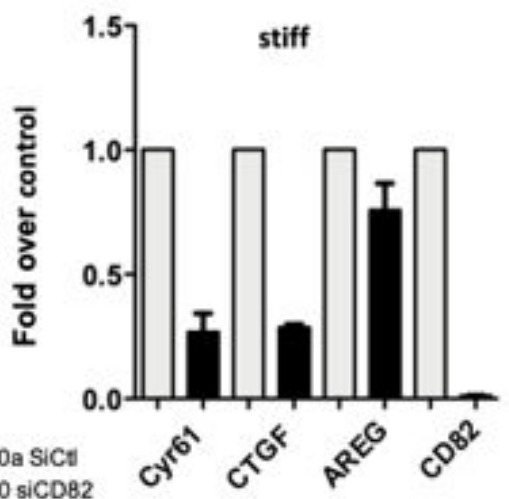

C

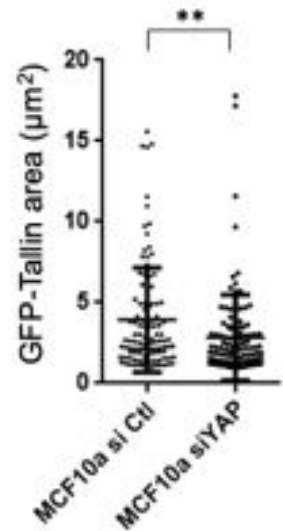

E

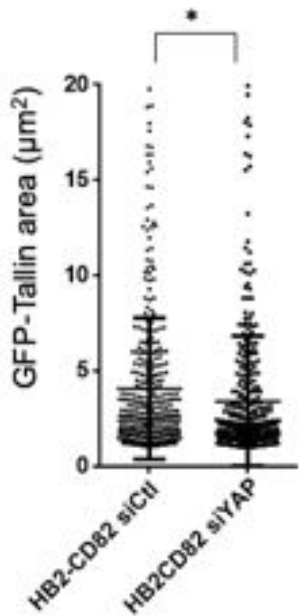

Figure 5. CD82 regulates and depends on YAP. (A) Representative RT QPCR analysis of YAP target genes in MCF10a transfected with Si Ctl or Si CD82 cultured on soft (left) and stiff (right) substrates (one experiment is shown here out of 3, done in triplicate). (B) Talin-GFP labelling in MCF10a cells transfected with Si Ctl or Si YAP C) Quantification of the size of the peripheral adhesion areas of 11 cells from 2 independent experiments; ${ }^{* *} p<0.01$. (D) Talin-GFP labelling in HB2-CD82 cells transfected with Si Ctl or Si YAP (E) Quantification of the size of the peripheral adhesion areas of 13 and 14 cells, respectively; ${ }^{*} p<0.05$.

Finally, we next studied whether YAP was required for the CD82 effects and we first studied its effect on MCF10a cell motility. We demonstrated that YAP-silenced cells explore 
a larger area in accordance with an increased in directionality (Figure S2C-E), a phenotype similar to the one observed in CD82-depleted cells. In addition, depletion of YAP induces a reduction in Talin-GFP adhesion sizes induced by CD82 in MCF10a (Figure 5B,C), with mean values $+/-$ SD $3.9+/-3.2$ and $2.8+/-2.6$ for MCF10a siCtl and siYAP, respectively, and HB2-CD82 (Figure 5D,E) mean values +/ - SD $4.0+/-3.7$ and 3.4 +/ - 3.4 for HB2CD82 siCtl and siYAP, respectively, indicating that YAP downregulation can revert the CD82 effect on focal adhesions. These results indicated that YAP is required for the effect of CD82 on adhesion sites.

\section{Discussion}

Cell mechanical properties regulate cell migration and can be finely tuned depending on the microenvironment. They can contribute to pathologies such as cancers when deregulated [43]. Our work reveals that expression of the metastasis suppressor tetraspanin CD82/KAI1, indicative of good prognosis in breast cancer, is a regulator of cell mechanics in breast epithelial cell lines. We propose that it regulates single-epithelial 2D cell migration through tuning of membrane tension which can induce caveolae disassembly and caveolin1 release. Through the caveolin pathway, the effect of CD82 expression on cell mechanical properties leads to the activation of the mechanosensor YAP/TAZ signaling pathway and YAP translocation into the nucleus. Our model (Figure 6) proposes that CD82 expression may contribute to maintain epithelial cells into an immobile state. Conversely, early loss of CD82 expression during carcinoma formation may contribute to release this constraint inducing migration of epithelial cells and can explain part of the metastasis-suppressor functions of CD82.

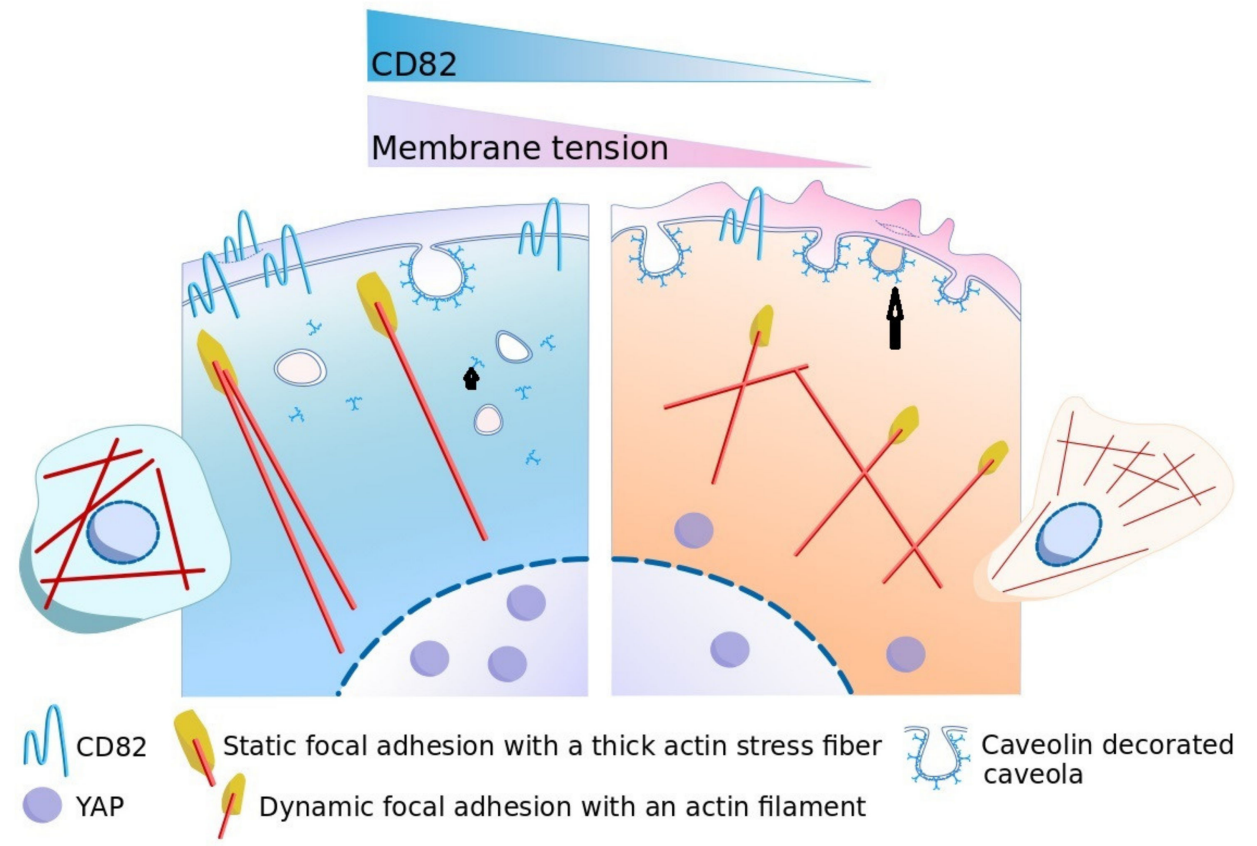

Figure 6. Model of CD82 action on 2D cell migration of epithelial cells. Left: In normal situations, CD82 is expressed and membrane tension is high; there are a few caveolae at the cell surface due to membrane tension buffering [18] and free caveolin-1 (black arrowhead). Free caveolin-1 can initiate a mechanotransduction cascade that drives YAP into the nucleus [21]. In turn, YAP controls caveolin-1 expression [26] and both YAP and caveolin-1 control focal adhesions [21,23] and actin polymerization [21,22] which also control membrane tension [16] and caveolae formation, looping a loop that keeps cells immobile. Right: When CD82 is poorly expressed, such as in breast carcinoma, the early loss of CD82 leads to a decrease in membrane tension, and an increase in cell surface caveolae (black arrow), allowing membrane tension fluctuations that, in synergy with actin polymerization fluctuations underneath the membrane [15] and with focal adhesion positioning at the leading edge [17], can form a stable lamellipodia required for persistent cell migration. 
As described above, we believe that the decrease in the cell surface density of caveolae induced by CD82 is the consequence of its ability to increase membrane tension. Even if we cannot exclude that CD82 could regulate membrane tension by directly affecting the caveolae system, it seems very unlikely since, even if both CD82 and caveolin are associated with membrane microdomains, no relationship between these two proteins within the plasma membrane has been clearly established. They are very rarely found to interact with each other (to our knowledge, only one paper describes their interaction [44]) and they are expressed in different membrane compartments. This interpretation is also supported by our results showing that CD82 is localized at the periphery of focal adhesions in some membrane projections where caveolin-1-GFP is not expressed. Interestingly, these projections are sometimes identified as migrasomes, some recently discovered cellular organelles that form as large vesicle-like structures [19], and we have clearly observed such structures in HB2 cells and showed that the shape of vesicles into the migrasomes are modified according to CD82 expression (EM picture in Figures $3 \mathrm{~F}$ and S5A,B). This may be a consequence of CD82 function in regulating membrane tension (CD82 is involved in the migrasome formation and/or could impair the release of its constituents that contributes to cell migration). It is tempting to propose that CD82 could act on membrane tension through the tetraspanin web but, at the same time, it is the unique tetraspanin clearly described so far as a metastasis suppressor. Indeed, CD81 functions in breast cancers are not clear, its expression being correlated to either bad or good prognosis [45]. Concerning CD9, we and others have shown that it can control cell migration but also often proliferation such as in parietal epithelial cells [46], as opposed to CD82 that is not affecting proliferation. Another interesting candidate is TSPAN7 that has an anti-tumor effect in some cancers such as bladder cancer [47] but not in others such as lung cancer [48].

Among the components of the plasma membrane that could be involved in CD82 regulation of membrane tension, lipids are also good candidates, especially cholesterol and glycosphingolipids (GSL). Indeed, cholesterol largely influences membrane order within biological membranes (reviewed in [49]), was recently proposed as a regulator of membrane tension by FLIM microscopy using the lipid probe FliptR [50] and it is also a key component of tetraspanin assemblies containing CD82. A direct link between CD82 and cholesterol was demonstrated by CD82 labeling with a photoactivatable cholesterol in vivo [51] and cholesterol/CD82 interplay is also supported by a recent publication showing that both CD82 and cholesterol are necessary and sufficient for migrasome formation during cell migration, modifying membrane line tension [19]. We also question the implication of GSL that are known to play an important role in the organization of CD82-enriched microdomains [12] and can modulate cell motility in epidermoid carcinoma cells [52]. GSL could regulate membrane tension through the glycosynapse via their glycosylation motives [53]. EGFR activity is sensitive to the level of GM3, a GSL that is regulated by CD82 [53], and this may contribute to the CD82-induced regulation of cell migration under EGF through the regulation of EGFR activity and endocytosis, maybe through the modulation of its dynamics and signaling as described in [54]. GSL could also link indirectly CD82 to caveolae since we previously found that the GSL GM1 is directly involved in the control of cell surface caveolae in fibroblasts [30] and it has been recently reported that caveolae transport gangliosides [55]. To finish, we consider one candidate that is specific for CD82 so far and named Kitenin, also called planar cell polarity protein or Van Gogh-like (Vangl)-1 protein [56]. This protein is a core component of the non-canonical Wnt planar cell polarity pathway that controls epithelial polarity and cell migration and that can play important role in collective movement for tissue organization and in cancers [57]. This protein interacts with CD82 and is structurally related to it with four transmembrane domains but shorter extracellular loops and it would be interesting to test its contribution to the CD82 effects.

We also found that CD82 regulates caveolin-1-induced YAP nucleo-shuttling on soft substrates and YAP transcriptional activity on both soft and stiff substrates. YAP nuclear localization and activity are tightly regulated by mechanisms that are still not completely 
understood. For example, a very recent work showed that it is the dynamics of nuclear YAP entry and exit that control YAP activity and not only its presence/absence in the nucleus [58]. Another work has shown that cell contractibility promotes tyrosine phosphorylation on additional YAP tyrosine residues by Src kinases, within the nucleus, and that this regulates its nuclear exit and that YAP nuclear exit is the limiting factor of YAP nucleo-shuttling [42]. Clearly, it will be very interesting to study the effect of CD82 on YAP nucleo-shuttling dynamics. We also believe that it could be interesting to study YAP post-translational modifications using proteomics. Indeed, YAP in the nucleus is generally associated with cell transformation and tumors, but is here surprisingly associated with anti-migratory properties. YAP is known to be regulated by many post-translational modifications (70 sites described in Phosphosite plus ${ }^{\mathrm{R}}$ ). Maybe CD82 favors a combination of these YAP post-translational modifications that drive YAP to induce an anti-migratory gene induction program that would be interesting to analyze using transcriptomic. However, YAP also has some functions independent from transcription and we observed a stronger effect of YAP downregulation on adhesion sizes that on its classical target genes mRNA regulation. Maybe YAP localization in the nucleus is also to deplete it from the cytoplasm and to regulate its cytoplasmic functions as we recently described for the junctional protein MAG1 [59]. Additionally, there exists up to eight different YAP1 isoforms due to splicing and some may have different functions [60]. Clearly, YAP functions and regulations are complex and more studies are needed to understand the full picture of CD82 function in breast epithelial cells.

As a conclusion, our results show that the anti-metastatic property of CD82 is probably a consequence of its impacts on membrane tension and cell mechanics, linked to caveolae mechanosensing and to the YAP/TAZ pathway.

Supplementary Materials: The following are available online at https://www.mdpi.com/article/ 10.3390/cells10061545/s1, Figure S1: CD82 expression and its effect on Talin-GFP, actin and YAP transcriptional targets in HB2 cells., Figure S2: CD82 expression and its effect on EGF-induced cell migration in MCF10a, Figure S3: CD82 expression and its effect on talin-GFP, actin and YAP transcriptional targets in MCF10a. Figure S4: Regulation of membrane tension and cell surface caveolae density in HB2 cells Figure S5: migrasomes and nuclei deformation induced by CD82. Movie S1: HB2 single cell migration, Movie S2: HB2-CD82 single cell migration., Movie S3: MCF10a cells transfected with Si Ctl single cell migration, Movie S4: MCF10a cells transfected with siCD82 single cell migration, Movie S5: Talin-GFP dynamics in 1 (out of 10) HB2 migrating cell., Movie S6: Talin-GFP dynamics in 1 (out of 10) HB2-CD82 migrating cell, Movie S7: Talin-GFP dynamics in 1 (out of 5) MCF10 si Ctl, Movie S8: Talin-GFP dynamics in 2 (out of 5) MCF10a siCD82, Movie S9: CaveolinGFP dynamics in 1 (out of 10) HB2 cells in iso (left) and after 5 min hypoosmotic (right) condition observed by TIRF microscopy Movie S10: Caveolin-GFP dynamics in 1 (out of 10) HB2-CD82 cell in iso (left) and after 5 min hypoosmotic (right) condition observed by TIRF microscopy.

Author Contributions: L.O. and C.B. performed experiments described in Figures S1-S4 and movies, with the help of A.L. and C.C. (Figure 1), L.C. (Luca Costa), C.C., A.C., and C.D. (Figure 3). L.F. participates in experiments and Figure S1; P.D. and L.C. (Luca Costa) participated in experiments analysis and Figures 3 and 4. D.K. and L.H.-M. participated in the RT and QPCR analysis. L.C. (Luca Costa), L.F. and C.D. participates in critically reading the manuscript. L.C. (Lucie Chauvin), F.B. and E.O. participated in materials supply. C.B. and P.-E.M. wrote the manuscript. All authors have read and agreed to the published version of the manuscript.

Funding: This research received no external funding.

Institutional Review Board Statement: Not applicable.

Informed Consent Statement: Not applicable.

Data Availability Statement: All the data provided in the manuscript and Supplementary Materials.

Acknowledgments: We gratefully thank Anna Castro, Cécile Gauthier-Rouvière, Stéphane Bodin and Franck Communale from the CNRS UMR 5237 Montpellier, France for the MCF10a cell line and helpful discussions, Alexandre Djiane IRCM, Inserm U1194 Montpellier, France, for helpful 
discussions, Pierre-Henri Puech, Adhesion and Inflammation Lab (LAI), INSERM U106, CNRS UMR 7333 Marseille, France for his help in membrane tether extraction experiments, Manouk Abkarian and Oscar Saavedra, CBS, Montpellier, France for their help in silicone gel preparation, Véronique Viguier and Franck Godiard of the MEA platform, Universite de Montpellier, France for TEM samples preparation and observation, Virginie Georget and Marie-Pierre Blanchard of the Montpellier RIO imaging platform for their help in image acquisition, Camille Lambert for technical help. This work was supported by a Cancéropôle Grand Sud Ouest Emergence and a Plan Cancer 2016 Equipment grants, France BioImaging (FBI, ANR10INSB04), the GIS IBISA (Infrastructures en Biologie Santé et Agronomie) and by the Labex EpiGenMed (ANR-10-LABX-12-0), an "Investissements d'avenir" program. LF was a recipient of the French Ministry of Education and Research and LC of the Fondation pour la Recherche Médicale. We are grateful to Zhanna Santybayeva for creating the graphical abstract.

Conflicts of Interest: The authors declare no competing interests.

\section{References}

1. Friedl, P.; Alexander, S. Cancer Invasion and the Microenvironment: Plasticity and Reciprocity. Cell 2011, 147, 992-1009. [CrossRef] [PubMed]

2. Yan, J.; Yang, Q.; Huang, Q. Metastasis Suppressor Genes. Histol. Histopathol. 2013, 28, 285-292. [CrossRef]

3. Tonoli, H.; Barrett, J.C. CD82 Metastasis Suppressor Gene: A Potential Target for New Therapeutics? Trends Mol. Med. 2005, 11, 563-570. [CrossRef] [PubMed]

4. Charrin, S.; Jouannet, S.; Boucheix, C.; Rubinstein, E. Tetraspanins at a Glance. J. Cell. Sci. 2014, 127, 3641-3648. [CrossRef] [PubMed]

5. Tsai, Y.C.; Weissman, A.M. Dissecting the Diverse Functions of the Metastasis Suppressor CD82/KAI1. FEBS Lett. 2011, 585, 3166-3173. [CrossRef] [PubMed]

6. Odintsova, E.; Sugiura, T.; Berditchevski, F. Attenuation of EGF Receptor Signaling by a Metastasis Suppressor, the Tetraspanin CD82/KAI-1. Curr. Biol. 2000, 10, 1009-1012. [CrossRef]

7. You, J.; Chang, R.; Liu, B.; Zu, L.; Zhou, Q. Nm23-H1 Was Involved in Regulation of KAI1 Expression in High-Metastatic Lung Cancer Cells L9981. J. Thorac. Dis. 2016, 8, 1217-1226. [CrossRef]

8. Liu, W.M.; Zhang, F.; Moshiach, S.; Zhou, B.; Huang, C.; Srinivasan, K.; Khurana, S.; Zheng, Y.; Lahti, J.M.; Zhang, X.A. Tetraspanin CD82 Inhibits Protrusion and Retraction in Cell Movement by Attenuating the Plasma Membrane-Dependent Actin Organization. PLoS ONE 2012, 7, e51797. [CrossRef]

9. Lee, J.; Byun, H.-J.; Lee, M.-S.; Jin, Y.-J.; Jeoung, D.; Kim, Y.-M.; Lee, H. The Metastasis Suppressor CD82/KAI1 Inhibits Fibronectin Adhesion-Induced Epithelial-to-Mesenchymal Transition in Prostate Cancer Cells by Repressing the Associated Integrin Signaling. Oncotarget 2017, 8, 1641-1654. [CrossRef]

10. Takahashi, M.; Sugiura, T.; Abe, M.; Ishii, K.; Shirasuna, K. Regulation of C-Met Signaling by the Tetraspanin KAI-1/CD82 Affects Cancer Cell Migration. Int. J. Cancer 2007, 121, 1919-1929. [CrossRef]

11. Termini, C.M.; Cotter, M.L.; Marjon, K.D.; Buranda, T.; Lidke, K.A.; Gillette, J.M. The Membrane Scaffold CD82 Regulates Cell Adhesion by Altering A4 Integrin Stability and Molecular Density. Mol. Biol. Cell 2014, 25, 1560-1573. [CrossRef] [PubMed]

12. Odintsova, E.; Butters, T.D.; Monti, E.; Sprong, H.; Van Meer, G.; Berditchevski, F. Gangliosides Play an Important Role in the Organization of CD82-Enriched Microdomains. Biochem. J. 2006, 400, 315. [CrossRef] [PubMed]

13. Bandyopadhyay, S.; Zhan, R.; Chaudhuri, A.; Watabe, M.; Pai, S.K.; Hirota, S.; Hosobe, S.; Tsukada, T.; Miura, K.; Takano, Y.; et al. Interaction of KAI1 on Tumor Cells with DARC on Vascular Endothelium Leads to Metastasis Suppression. Nat. Med. 2006, 12, 933-938. [CrossRef]

14. Hur, J.; Choi, J.-I.; Lee, H.; Nham, P.; Kim, T.-W.; Chae, C.-W.; Yun, J.-Y.; Kang, J.-A.; Kang, J.; Lee, S.E.; et al. CD82/KAI1 Maintains the Dormancy of Long-Term Hematopoietic Stem Cells through Interaction with DARC-Expressing Macrophages. Cell Stem Cell 2016, 18, 508-521. [CrossRef]

15. Mueller, J.; Szep, G.; Nemethova, M.; de Vries, I.; Lieber, A.D.; Winkler, C.; Kruse, K.; Small, J.V.; Schmeiser, C.; Keren, K.; et al. Load Adaptation of Lamellipodial Actin Networks. Cell 2017, 171, 188-200.e16. [CrossRef]

16. Diz-Muñoz, A.; Krieg, M.; Bergert, M.; Ibarlucea-Benitez, I.; Muller, D.J.; Paluch, E.; Heisenberg, C.-P. Control of Directed Cell Migration in Vivo by Membrane-to-Cortex Attachment. PLoS Biol. 2010, 8, e1000544. [CrossRef] [PubMed]

17. Pontes, B.; Monzo, P.; Gole, L.; Le Roux, A.-L.; Kosmalska, A.J.; Tam, Z.Y.; Luo, W.; Kan, S.; Viasnoff, V.; Roca-Cusachs, P.; et al. Membrane Tension Controls Adhesion Positioning at the Leading Edge of Cells. J. Cell Biol. 2017, 216, 2959-2977. [CrossRef]

18. Sinha, B.; Köster, D.; Ruez, R.; Gonnord, P.; Bastiani, M.; Abankwa, D.; Stan, R.V.; Butler-Browne, G.; Vedie, B.; Johannes, L.; et al. Cells Respond to Mechanical Stress by Rapid Disassembly of Caveolae. Cell 2011, 144, 402-413. [CrossRef]

19. Huang, Y.; Zucker, B.; Zhang, S.; Elias, S.; Zhu, Y.; Chen, H.; Ding, T.; Li, Y.; Sun, Y.; Lou, J.; et al. Migrasome Formation Is Mediated by Assembly of Micron-Scale Tetraspanin Macrodomains. Nat. Cell Biol. 2019, 21, 991-1002. [CrossRef]

20. Parton, R.G.; Del Pozo, M.A.; Vassilopoulos, S.; Nabi, I.R.; Le Lay, S.; Lundmark, R.; Kenworthy, A.K.; Camus, A.; Blouin, C.M.; Sessa, W.C.; et al. Caveolae: The FAQs. Traffic 2020, 21, 181-185. [CrossRef] 
21. Moreno-Vicente, R.; Pavón, D.M.; Martín-Padura, I.; Català-Montoro, M.; Díez-Sánchez, A.; Quílez-Álvarez, A.; López, J.A.; Sánchez-Álvarez, M.; Vázquez, J.; Strippoli, R.; et al. Caveolin-1 Modulates Mechanotransduction Responses to Substrate Stiffness through Actin-Dependent Control of YAP. Cell Rep. 2018, 25, 1622-1635.e6. [CrossRef]

22. Qiao, Y.; Chen, J.; Lim, Y.B.; Finch-Edmondson, M.L.; Seshachalam, V.P.; Qin, L.; Jiang, T.; Low, B.C.; Singh, H.; Lim, C.T.; et al. YAP Regulates Actin Dynamics through ARHGAP29 and Promotes Metastasis. Cell Rep. 2017, 19, 1495-1502. [CrossRef] [PubMed]

23. Mason, D.E.; Collins, J.M.; Dawahare, J.H.; Nguyen, T.D.; Lin, Y.; Voytik-Harbin, S.L.; Zorlutuna, P.; Yoder, M.C.; Boerckel, J.D. YAP and TAZ Limit Cytoskeletal and Focal Adhesion Maturation to Enable Persistent Cell Motility. J. Cell Biol. 2019, 218, 1369-1389. [CrossRef] [PubMed]

24. Park, J.; Kim, D.-H.; Shah, S.R.; Kim, H.-N.; Kim, P.; Quiñones-Hinojosa, A.; Levchenko, A. Switch-like Enhancement of EpithelialMesenchymal Transition by YAP through Feedback Regulation of WT1 and Rho-Family GTPases. Nat. Commun. 2019, 10, 2797. [CrossRef] [PubMed]

25. Shen, J.; Cao, B.; Wang, Y.; Ma, C.; Zeng, Z.; Liu, L.; Li, X.; Tao, D.; Gong, J.; Xie, D. Hippo Component YAP Promotes Focal Adhesion and Tumour Aggressiveness via Transcriptionally Activating THBS1/FAK Signalling in Breast Cancer. J. Exp. Clin. Cancer Res. 2018, 37, 175. [CrossRef]

26. Rausch, V.; Bostrom, J.R.; Park, J.; Bravo, I.R.; Feng, Y.; Hay, D.C.; Link, B.A.; Hansen, C.G. The Hippo Pathway Regulates Caveolae Expression and Mediates Flow Response via Caveolae. Curr. Biol. 2019, 29, 242-255.e6. [CrossRef]

27. Rubinstein, E.; Le Naour, F.; Lagaudriere-Gesbert, C.; Billard, M.; Conjeaud, H.; Boucheix, C. CD9, CD63, CD81, and CD82 Are Components of a Surface Tetraspan Network Connected to HLA-DR and VLA Integrins. Eur. J. Immunol. 1996, 26, $2657-2665$. [CrossRef]

28. Vera, J.; Lartigue, L.; Vigneron, S.; Gadea, G.; Gire, V.; Del Rio, M.; Soubeyran, I.; Chibon, F.; Lorca, T.; Castro, A. Greatwall Promotes Cell Transformation by Hyperactivating AKT in Human Malignancies. Elife 2015, 4. [CrossRef]

29. Gorelik, R.; Gautreau, A. Quantitative and Unbiased Analysis of Directional Persistence in Cell Migration. Nat. Protoc. 2014, 9 , 1931-1943. [CrossRef]

30. Veracini, L.; Simon, V.; Richard, V.; Schraven, B.; Horejsi, V.; Roche, S.; Benistant, C. The Csk-Binding Protein PAG Regulates PDGF-Induced Src Mitogenic Signaling via GM1. J. Cell Biol. 2008, 182, 603-614. [CrossRef]

31. Sadoun, A.; Puech, P.-H. Quantifying CD95/Cl-CD95L Implications in Cell Mechanics and Membrane Tension by Atomic Force Microscopy Based Force Measurements. Methods Mol. Biol. 2017, 1557, 139-151. [CrossRef] [PubMed]

32. Gavara, N. A Beginner's Guide to Atomic Force Microscopy Probing for Cell Mechanics. Microsc. Res. Technique. 2017, 80, 75-84. [CrossRef] [PubMed]

33. Saavedra, V.O.; Fernandes, T.F.D.; Milhiet, P.-E.; Costa, L. Compression, Rupture, and Puncture of Model Membranes at the Molecular Scale. Langmuir 2020, 36, 5709-5716. [CrossRef]

34. Tejera, E.; Rocha-Perugini, V.; López-Martín, S.; Pérez-Hernández, D.; Bachir, A.I.; Horwitz, A.R.; Vázquez, J.; Sánchez-Madrid, F.; Yáñez-Mo, M. CD81 Regulates Cell Migration through Its Association with Rac GTPase. Mol. Biol. Cell 2013, 24, $261-273$. [CrossRef]

35. Odintsova, E.; van Niel, G.; Conjeaud, H.; Raposo, G.; Iwamoto, R.; Mekada, E.; Berditchevski, F. Metastasis Suppressor Tetraspanin CD82/KAI1 Regulates Ubiquitylation of Epidermal Growth Factor Receptor. J. Biol. Chem. 2013, 288 , 26323-26334. [CrossRef]

36. Lorentzen, A.; Becker, P.F.; Kosla, J.; Saini, M.; Weidele, K.; Ronchi, P.; Klein, C.; Wolf, M.J.; Geist, F.; Seubert, B.; et al. Single Cell Polarity in Liquid Phase Facilitates Tumour Metastasis. Nat. Commun. 2018, 9, 887. [CrossRef]

37. Vicente-Manzanares, M.; Webb, D.J.; Horwitz, A.R. Cell Migration at a Glance. J. Cell Sci. 2005, 118, 4917-4919. [CrossRef]

38. Burridge, K. Focal Adhesions: A Personal Perspective on a Half Century of Progress. FEBS J. 2017, 284, 3355-3361. [CrossRef]

39. Totaro, A.; Panciera, T.; Piccolo, S. YAP/TAZ Upstream Signals and Downstream Responses. Nat. Cell Biol. 2018, 20, 888-899. [CrossRef]

40. Vidi, P.-A.; Maleki, T.; Ochoa, M.; Wang, L.; Clark, S.M.; Leary, J.F.; Lelièvre, S.A. Disease-on-a-Chip: Mimicry of Tumor Growth in Mammary Ducts. Lab. Chip 2014, 14, 172-177. [CrossRef] [PubMed]

41. Elosegui-Artola, A.; Andreu, I.; Beedle, A.E.M.; Lezamiz, A.; Uroz, M.; Kosmalska, A.J.; Oria, R.; Kechagia, J.Z.; Rico-Lastres, P.; Le Roux, A.-L.; et al. Force Triggers YAP Nuclear Entry by Regulating Transport across Nuclear Pores. Cell 2017, 171, 1397-1410.e14. [CrossRef]

42. Ege, N.; Dowbaj, A.M.; Jiang, M.; Howell, M.; Hooper, S.; Foster, C.; Jenkins, R.P.; Sahai, E. Quantitative Analysis Reveals That Actin and Src-Family Kinases Regulate Nuclear YAP1 and Its Export. Cell Syst. 2018, 6, 692-708.e13. [CrossRef] [PubMed]

43. Northcott, J.M.; Dean, I.S.; Mouw, J.K.; Weaver, V.M. Feeling Stress: The Mechanics of Cancer Progression and Aggression. Front. Cell Dev. Biol. 2018, 6, 17. [CrossRef] [PubMed]

44. Wang, X.; Yan, Q.; Sun, P.; Liu, J.-W.; Go, L.; McDaniel, S.M.; Paller, A.S. Suppression of Epidermal Growth Factor Receptor Signaling by Protein Kinase C-Alpha Activation Requires CD82, Caveolin-1, and Ganglioside. Cancer Res. 2007, 67, $9986-9995$. [CrossRef] [PubMed]

45. Vences-Catalán, F.; Kuo, C.-C.; Sagi, Y.; Chen, H.; Kela-Madar, N.; van Zelm, M.C.; van Dongen, J.J.M.; Levy, S. A Mutation in the Human Tetraspanin CD81 Gene Is Expressed as a Truncated Protein but Does Not Enable CD19 Maturation and Cell Surface Expression. J. Clin. Immunol. 2015, 35, 254-263. [CrossRef] 
46. Lazareth, H.; Henique, C.; Lenoir, O.; Puelles, V.G.; Flamant, M.; Bollée, G.; Fligny, C.; Camus, M.; Guyonnet, L.; Millien, C.; et al. The Tetraspanin CD9 Controls Migration and Proliferation of Parietal Epithelial Cells and Glomerular Disease Progression. Nat. Commun. 2019, 10, 3303. [CrossRef]

47. Yu, X.; Li, S.; Pang, M.; Du, P.; Xu, T.; Bai, T.; Yang, T.; Hu, J.; Zhu, S.; Wang, L.; et al. TSPAN7 Exerts Anti-Tumor Effects in Bladder Cancer Through the PTEN/PI3K/AKT Pathway. Front. Oncol. 2020, 10, 613869. [CrossRef]

48. Wang, X.; Lin, M.; Zhao, J.; Zhu, S.; Xu, M.; Zhou, X. TSPAN7 promotes the migration and proliferation of lung cancer cells via epithelial-to-mesenchymal transition. OncoTargets Therapy. 2018, 11, 8815-8822. [CrossRef]

49. Pike, L.J. Lipid Rafts: Bringing Order to Chaos. J. Lipid. Res. 2003, 44, 655-667. [CrossRef]

50. Colom, A.; Derivery, E.; Soleimanpour, S.; Tomba, C.; Molin, M.D.; Sakai, N.; González-Gaitán, M.; Matile, S.; Roux, A. A Fluorescent Membrane Tension Probe. Nat. Chem. 2018, 10, 1118-1125. [CrossRef]

51. Charrin, S.; Manié, S.; Thiele, C.; Billard, M.; Gerlier, D.; Boucheix, C.; Rubinstein, E. A Physical and Functional Link between Cholesterol and Tetraspanins. Eur. J. Immunol. 2003, 33, 2479-2489. [CrossRef] [PubMed]

52. Park, S.-Y.; Yoon, S.-J.; Freire-de-Lima, L.; Kim, J.-H.; Hakomori, S. Control of Cell Motility by Interaction of Gangliosides, Tetraspanins, and Epidermal Growth Factor Receptor in A431 versus KB Epidermoid Tumor Cells. Carbohydr. Res. 2009, 344, 1479-1486. [CrossRef]

53. Regina Todeschini, A.; Hakomori, S. Functional Role of Glycosphingolipids and Gangliosides in Control of Cell Adhesion, Motility, and Growth, through Glycosynaptic Microdomains. Biochim. Biophys. Acta 2008, 1780, 421-433. [CrossRef] [PubMed]

54. Danglot, L.; Chaineau, M.; Dahan, M.; Gendron, M.-C.; Boggetto, N.; Perez, F.; Galli, T. Role of TI-VAMP and CD82 in EGFR Cell-Surface Dynamics and Signaling. J. Cell Sci. 2010, 123, 723-735. [CrossRef] [PubMed]

55. Shvets, E.; Bitsikas, V.; Howard, G.; Hansen, C.G.; Nichols, B.J. Dynamic Caveolae Exclude Bulk Membrane Proteins and Are Required for Sorting of Excess Glycosphingolipids. Nat. Commun. 2015, 6, 6867. [CrossRef]

56. Lee, J.H.; Park, S.R.; Chay, K.-O.; Seo, Y.-W.; Kook, H.; Ahn, K.Y.; Kim, Y.J.; Kim, K.K. KAI1 COOH-Terminal Interacting Tetraspanin (KITENIN), a Member of the Tetraspanin Family, Interacts with KAI1, a Tumor Metastasis Suppressor, and Enhances Metastasis of Cancer. Cancer Res. 2004, 64, 4235-4243. [CrossRef] [PubMed]

57. Smith, P.; Godde, N.; Rubio, S.; Tekeste, M.; Vladar, E.K.; Axelrod, J.D.; Henderson, D.J.; Milgrom-Hoffman, M.; Humbert, P.O.; Hinck, L. VANGL2 Regulates Luminal Epithelial Organization and Cell Turnover in the Mammary Gland. Sci. Rep. 2019, 9, 7079. [CrossRef]

58. Franklin, J.M.; Ghosh, R.P.; Shi, Q.; Reddick, M.P.; Liphardt, J.T. Concerted Localization-Resets Precede YAP-Dependent Transcription. Nat. Commun. 2020, 11, 4581. [CrossRef]

59. Kantar, D.; Mur, E.B.; Mancini, M.; Slaninova, V.; Salah, Y.B.; Costa, L.; Forest, E.; Lassus, P.; Géminard, C.; Boissière-Michot, F.; et al. MAGI1 Inhibits the AMOTL2/P38 Stress Pathway and Prevents Luminal Breast Tumorigenesis. Sci. Rep. 2021, 11, 5752. [CrossRef]

60. Srivastava, D.; de Toledo, M.; Manchon, L.; Tazi, J.; Juge, F. Modulation of Yorkie Activity by Alternative Splicing Is Required for Developmental Stability. EMBO J. 2021, 40, e104895. [CrossRef] [PubMed] 